\title{
Role of oxidative stress in elevated blood pressure induced by high free fatty acids
}

\author{
Hui Wang ${ }^{1,2,4}$, Hongliang $\mathrm{Li}^{1,3,4}$, Zhiqiang Hou ${ }^{1}$, Lin $\operatorname{Pan}^{1}$, Xiaoxia Shen ${ }^{1}$ and Guangwei $\mathrm{Li}^{1}$
}

The aim of the study is to investigate the possible mechanism of oxidative stress in the high free fatty acids (FFAs)-induced hypertension. Male Sprague-Dawley rat models were established and classified into three groups, namely the control group (NC group), the FFA group, and the $\mathrm{N}$-acetylcysteine (NAC) group. Blood pressure (BP) was recorded. An organ chamber experiment was performed to determine endothelium-dependent/-independent vasodilation (EDV/EIV). Reactive oxygen species (ROS), nitrotyrosine, reduced glutathione hormone (GSH) and $\mathrm{NO}_{2}-\mathrm{NO}_{3}{ }^{-}$levels were measured in plasma. Endothelial nitric oxide synthase (eNOS) mRNA expression in endothelial cells was evaluated by real-time PCR. The following results were observed: (1) In the FFA group, BP increased after $4 \mathrm{~h}$ infusion of Intralipid+heparin. In the NAC group, systolic and diastolic BP remained the same. (2) In the FFA group, the aortic rings tended to show impaired EDV in response to acetylcholine (ACh). There was no difference of EDV response in the NAC and NC groups. (3) In the FFA group, $\mathrm{NO}_{2}{ }^{-} / \mathrm{NO}_{3}{ }^{-}$levels were significantly reduced, and eNOS mRNA expression and activity were significantly decreased compared with the NC group. NAC administration increased eNOS mRNA expression and activity. (4) ROS and nitrotyrosine concentrations in the FFA group were higher than in the NC group, and GSH concentrations in the FFA group were lower than in the NC group. Elevated FFAs can induce elevated BP, potentially through FFA-induced impairment of EDV resulting from decreased eNOS mRNA expression and activity. Oxidative stress may also play an important role in potential mechanisms of this high FFA-induced elevated BP.

Hypertension Research (2009) 32, 152-158; doi:10.1038/hr.2008.35; published online 23 January 2009

Keywords: blood pressure; endothelium-dependent vasodilation; eNOS; free fatty acids; oxidative stress

\section{INTRODUCTION}

Numerous studies support a link between insulin resistance (IR) and hypertension; however, the mechanisms are largely unknown. There is some evidence that elevated plasma non-esterified fatty acids (NEFAs) may be involved in this process. For instance, the levels of NEFAs in hypertensive patients were higher than those in healthy subjects, ${ }^{1}$ whereas in a Paris Prospective Study, a high free fatty acids (FFAs) level was an independent risk factor for hypertension. ${ }^{2}$ Further, resistance to the NEFA-lowering action of insulin was severely impaired in abdominally obese hypertensive patients, and correlated with blood pressure (BP) independently of insulin and insulinmediated glucose disposal. ${ }^{3}$ Experimentally, rats that were fed a high-fat diet for 8 weeks had increased plasma NEFAs and a $12 \mathrm{~mm} \mathrm{Hg}$ increase in systolic BP. ${ }^{4}$

High levels of FFAs have been shown to directly elevate BP. For instance, Stojiljkovic et al. ${ }^{5}$ reported that a 4 -h infusion of Intralipid+heparin in normal volunteers induced a significant increase in systolic $(13.5 \pm 2.1 \mathrm{~mm} \mathrm{Hg})$ and diastolic $(8.0 \pm 1.5 \mathrm{~mm} \mathrm{Hg}) \mathrm{BP}$, as well as in heart rate $(9.4 \pm 1.4$ b.p.m.). In minipigs, BP and vascular resistance in most tissue beds increased when plasma NEFAs were elevated during an infusion of Intralipid+heparin, ${ }^{6}$ whereas an infusion of oleic acid into the portal veins of rats induced a significant increase in BP, which was blocked by $\alpha_{1}$-adrenoceptor antagonists. ${ }^{7}$ Thus, these data suggest that high FFAs may contribute to elevated BP.

Although the mechanisms by which high FFAs induce elevated BP are largely unknown, high FFAs can decrease endothelial nitric oxide synthase (eNOS) activity and impair endothelium-dependent vasodilation (EDV) in vitro. ${ }^{8}$ In humans, EDV and nitric oxide (NO) production are impaired when NEFAs are increased by an Intralipid+heparin infusion. ${ }^{9-11}$ Furthermore, EDV can be induced by impaired eNOS activity and reduced NO production. However, the relationship between the elevation of BP caused by FFAs and the impairment of EDV, which can also be caused by FFAs, has not been clarified.

Interestingly, earlier studies have shown that hypertension is related to oxidative stress. Acutely raising lipids with a short-term infusion of Intralipid+heparin, which mimics and/or exacerbates the dyslipidemia seen with IR, increases $\mathrm{BP}$ and elevates $\mathrm{F}_{2}$-isoprostanes, a biomarker of oxidative stress. ${ }^{5,12}$ Moreover, in experimental models, reducing the

${ }^{1}$ Department of Endocrinology, China-Japan Friendship Hospital, Beijing, China; ${ }^{2}$ Graduate School, Peking Union Medical College, Tsinghua University, Beijing, China; ${ }^{3}$ Vascular Biology Unit, Department of Medicine, Boston University School of Medicine, Boston, MA, USA

Correspondence: Professor G Li, Department of Endocrinology, China-Japan Friendship Hospital, Beijing 100029, China or Dr H Li, Vascular Biology Unit, Department of Medicine, Boston University School of Medicine, Boston, MA 02118, USA.

E-mail: guangwei.li@hotmail.com, lihongliang1991@yahoo.com.cn

${ }^{4}$ These authors contributed equally to this work.

Received 12 September 2008; revised 17 December 2008; accepted 18 December 2008; published online 23 January 2009 
antioxidant capacity by the depletion of glutathione hormone (GSH) produces severe hypertension, ${ }^{13}$ whereas the Dietary Approaches to Stop Hypertension Combination Diet (DASH-CD) may decrease BP in obese hypertensive patients by enhancing the antioxidant capacity. ${ }^{14}$ Oxidative stress has also been shown to induce endothelial dysfunction. For example, Perticone et al. ${ }^{15}$ reported that obesity and body fat distribution induced endothelial dysfunction by oxidative stress. FFAsinduced endothelial dysfunction can be corrected by vitamin C, ${ }^{16}$ whereas FFAs can stimulate reactive oxygen species (ROS) production through the protein kinase C-dependent activation of $\mathrm{NAD}(\mathrm{P}) \mathrm{H}$ oxidase. ${ }^{17}$ Thus, oxidative stress induced by FFAs quite likely plays an important role in the link between endothelial dysfunction and high BP.

The aim of this study was to not only examine whether the FFAsinduced elevation of BP was related to the FFAs-induced impairment of EDVbut also to determine the role of oxidative stress in mediating FFAs-induced BP elevation.

\section{METHODS}

\section{Animals and diet}

Male Sprague-Dawley rats ( 12 weeks of age; weight $280-320 \mathrm{~g}$ ) were fed normal chow $(66.5 \%$ carbohydrate, $10.2 \%$ fat, and $23.3 \%$ protein). All animals had free access to their diet and drinking water. Housing was at a constant temperature of $21 \pm 1{ }^{\circ} \mathrm{C}$ in a 12-h light/dark cycle. All animal care and experimental procedures were in accordance with the guidelines of the Animal Care Committee of the China-Japan Friendship Hospital of China.

\section{Experimental design}

Rats were assigned to three groups, namely the control group (NC group, $N=20$ ), the FFA group $(N=22)$, and the $N$-acetylcysteine group (NAC group, $N=23)$. The NC group received a 4 -h infusion of saline $\left(18 \mu \mathrm{min}^{-1}\right)$, the FFA group received a 4-h infusion of $20 \%$ Fat Emulsion (Intralipid; Baxter Qiaoguang Healthcare Co., Ltd, Guangzhou, China) $\left(18 \mu \mathrm{min}^{-1}\right)+$ heparin $\left(0.72 \mathrm{IU} \mathrm{min}^{-1}\right)$, and the NAC group received a 4 -h infusion of Intralipid $\left(18 \mu \mathrm{min}^{-1}\right)+$ heparin $\left(0.72 \mathrm{IU} \mathrm{min}^{-1}\right)$ and NAC $\left(2.76 \mu \mathrm{mol} \mathrm{kg}^{-1} \mathrm{~min}^{-1}\right)$.

\section{Biochemical measurements}

Blood for NEFAs was drawn into prechilled eppendorf tubes containing disodium EDTA and paraoxon (Sigma-Aldrich, St Louis, MO, USA) to inhibit lipoprotein lipase and prevent hydrolysis of NEFAs from triglycerides in vitro. Plasma was stored at $-70^{\circ} \mathrm{C}$ before the analysis of total plasma NEFAs by the ${ }^{63} \mathrm{Ni}$ method. ${ }^{5}$

The serum ROS concentration was determined by the method of Fenton reaction and Gress coloration. ${ }^{18}$ The determination was carried out according to the instruction manual provided by the manufacturer (Jiancheng Bioengineering Ltd, Nanjing, China).

GSH concentration was estimated by the DTNB (5,5'-dithiobis(2-nitrobenzoic acid)) reduction method. ${ }^{19,20}$ The formation of a GSH-DTNB conjugate was monitored by the change in absorbance at $412 \mathrm{~nm}$. The determination was carried out according to the manufacturer's protocol (Jiancheng Bioengineering Ltd).

Nitrotyrosine concentration was determined by ELISA, as described earlier. ${ }^{21,22}$ ELISA plates were coated with samples or bovine serum albumin standard samples in $50 \mathrm{mmoll}^{-1}$ of $\mathrm{Na}_{2} \mathrm{CO}-\mathrm{NaHCO}_{3}$ buffer at $\mathrm{pH} 9.6$ and allowed to bind overnight at $4{ }^{\circ} \mathrm{C}$. Nonspecific binding was blocked by $1 \%$ of bovine serum albumin in PBS plus $0.05 \%$ of Tween 20 for $1 \mathrm{~h}$ at $37^{\circ} \mathrm{C}$, and the wells were then incubated with $5 \mu \mathrm{g} \mathrm{ml}^{-1}$ of purified mouse monoclonal antinitrotyrosine IgG for $1 \mathrm{~h}$ at $37^{\circ} \mathrm{C}$ and with a peroxidase-conjugated goat antirat IgG secondary antibody for $45 \mathrm{~min}$ at $37^{\circ} \mathrm{C}$. The peroxidase reaction product was generated using a peroxidase substrate. Plates were incubated for $10 \mathrm{~min}$ at room temperature, and optical density was read at $492 \mathrm{~nm}$ in a microplate reader.

\section{Hyperinsulinemic-euglycemic clamp}

Two hours before the end of infusion, the hyperinsulinemic-euglycemic clamp technique was performed as described earlier. ${ }^{23}$ In brief, experiments were performed in Sprague-Dawley rats fasted for $8-10 \mathrm{~h}$ with free access to water. The hyperinsulinemic clamp $\left(12 \mathrm{mU} \mathrm{kg}^{-1} \mathrm{~min}^{-1}\right.$ of human insulin; Novo Nordisk A/S, Bagsværd, Denmark) was performed constantly. The glucose concentrations were clamped at euglycemic levels $\left(5 \mathrm{mmoll}^{-1}\right)$ by an infusion of $20 \%$ glucose, and the plasma glucose concentration was determined with a Beckman Glucose Analyzer II (Beckman Instruments, Fullerton, CA, USA). The glucose infusion rate (GIR) was used to evaluate insulin sensitivity.

\section{BP measurement}

A 60-min equilibration period was allowed after surgery for stabilization of BP. Measurements were performed as described earlier. ${ }^{24}$ In brief, rats were anesthetized using pentobarbital (Nembutal; $50 \mathrm{mg}$ per $\mathrm{kg}$ body weight), and polyethylene cannulas (PE-50; IntraMedic AB, Balsta, Sweden) were surgically implanted into the carotid artery for arterial sampling and measurement of BP $\left({ }^{*}\right.$ IPS100C ${ }^{\star}$; BIOPAC System Inc., Goleta City, CA, USA) and into both jugular veins for continuous administration of anesthetic and other intravenous infusions. A tracheotomy tube was inserted and animals were allowed to spontaneously breathe room air throughout the course of the experiment. The surgical procedure lasted approximately $30 \mathrm{~min}$, and the animals were maintained under anesthesia for the duration of the experiment using a continuous pentobarbital infusion through the left jugular cannula. Body temperature was maintained using a water-jacketed platform and a heating lamp positioned above the rat.

Heart rate and BP data were acquired with an IBM-compatible computer $(100 \mathrm{~Hz}$ sampling frequency) using WINDAQ data acquisition software (DATAQ Instruments, Akron, OH, USA).

\section{Organ chamber experiment}

The aortic rings were prepared as described earlier. ${ }^{25-27}$ In brief, the rats were anesthetized with pentobarbital ( $60 \mathrm{mg}$ per $\mathrm{kg}$ body weight, i.p.), the descending thoracic aorta was dissected, cut into small rings ( $3-5 \mathrm{~mm}$ in width), and suspended in a 5-ml organ bath containing normal Krebs physiological salt solution. The bathing solution was gassed continuously with $95 \%$ oxygen and $5 \%$ carbon dioxide at $37^{\circ} \mathrm{C}(\mathrm{pH} \mathrm{7.4})$. Isometric tension (g) was measured using a force displacement transducer connected to a Mac Lab recording system (World Precision Instruments Inc., Sarasota, FL, USA). Aortic rings were progressively stretched to an optimal basal tension of $1 \mathrm{~g}$ and allowed to equilibrate for $45 \mathrm{~min}$. During this period, the bathing solution was replaced every $15 \mathrm{~min}$ and, if required, the basal tone was readjusted to $1 \mathrm{~g}$. The aortic rings were then repeatedly stimulated with the $\mathrm{KCl}$ solution (high $\mathrm{K}^{+}, 80 \mathrm{~mm}$ ) for $5 \mathrm{~min}$ at 10 -min intervals until two consecutive equal contractions were attained showing tissue stability.

After the washout of high $\mathrm{K}^{+}$responses, the aortic rings were incubated for 20 min with cumulative concentration-response curves to the respective endothelium-dependent and endothelium -independent relaxant agonists acetylcholine (ACh; $10^{-8}$ to $10^{-3} \mathrm{M}$ ) and sodium nitroprusside (SNP; $10^{-9}$ to $10^{-4} \mathrm{M}$ ). To test the relaxation responses to ACh and SNP, the aortic rings were pre-contracted with PE $(1 \mu \mathrm{M})$. ACh was used as an agonist to elicit the endothelium-dependent receptor-mediated relaxation. SNP was used as an exogenous NO donor to examine the endothelium-independent smooth muscle cell response.

\section{eNOS enzymatic activity}

eNOS enzymatic activity was determined as described earlier. ${ }^{28}$ Aortas were rapidly frozen in liquid nitrogen and homogenized in a lysis buffer ( $25 \mathrm{mmoll}^{-1}$ Tris- $\mathrm{HCl}$, pH 7.4, $1 \mathrm{mmoll}^{-1}$ EDTA, $1 \mathrm{mmoll}^{-1}$ EGTA (ethylene glycol bis( $\beta$-aminoethylether)- $N, N, N^{\prime}, N^{\prime}$,-tetraacetic acid), $0.1 \mathrm{mmoll}^{-1} \mathrm{NaF}$ and $\left.0.1 \mathrm{mmoll}^{-1} \mathrm{Na}_{3} \mathrm{VO}_{4}\right)$. A total of $50 \mu \mathrm{g}$ of protein extract were incubated at room temperature for $30 \mathrm{~min}$ with a reaction buffer $\left(50 \mathrm{mmol}^{-1}\right.$ Tris- $\mathrm{HCl}$, $\mathrm{pH} 7.4,0.3 \mu \mathrm{moll}^{-1} \mathrm{BH}_{4}, 1 \mu \mathrm{moll}^{-1} \mathrm{FAD}$ (flavine adenine dinucleotide), $1 \mu \mathrm{moll}^{-1} \mathrm{FMN}$ (flavine mononucleotide), $1 \mathrm{mmoll}^{-1} \mathrm{NADPH}$ and $0.5 \mu \mathrm{Ci}$ ${ }^{14} \mathrm{C}$-arginine, with or without $1 \mathrm{mmoll}^{-1} \mathrm{CaCl}_{2}$ ). The reaction was blocked on ice for $10 \mathrm{~min}$ with a stop buffer (20 $\mathrm{mmoll}^{-1}$ HEPES (4-(2-hydroxyethyl)-1- 
piperazineethanesulfonic acid) and $5 \mathrm{mmoll}^{-1} \mathrm{EDTA}$ ). The reaction mix was applied to a 1-ml column containing Dowex AG $50 \times 8$ resin that had been equilibrated with the stop buffer. ${ }^{14} \mathrm{C}$-citrulline was eluted twice with $2 \mathrm{ml}$ of water, and radioactivity was determined by scintillation counting.

\section{Isolation of total RNA and real-time PCR}

Total RNA was isolated from the endothelial cells using a TRIzol reagent (Gibco BRL, Invitrogen Corporation, Carlsbad, CA, USA). cDNA synthesis was performed using a ReverTraAce- $\alpha$ Kit (Toyobo Co., Ltd, Osaka, Japan) according to the manufacturer's instructions in a total volume of $20 \mu \mathrm{l}$ under conditions of $42^{\circ} \mathrm{C}$ for $20 \mathrm{~min}, 99^{\circ} \mathrm{C}$ for $5 \mathrm{~min}$ and $4{ }^{\circ} \mathrm{C}$ for $5 \mathrm{~min}$. Quantitative real-time PCR amplification was performed using an SYBR Green PCR Master Mix (Toyobo Co., Ltd) in a total volume of $50 \mu \mathrm{l}$ according to the manufacturer's instructions. The reaction conditions were 40 cycles of $95^{\circ} \mathrm{C}$ for $1 \mathrm{~min}$, $95^{\circ} \mathrm{C}$ for $15 \mathrm{~s}, 55-60^{\circ} \mathrm{C}$ for $15 \mathrm{~s}$ and $72{ }^{\circ} \mathrm{C}$ for $45 \mathrm{~s}$, and the amplification was carried out using an ABI 7300 Sequence Detection System (Applied Biosystems, Foster City, CA, USA). The sequences of the primers used were described earlier. ${ }^{29}$ The sense primer, $5^{\prime}$-CCTTCCGCTACCAGCCTGA- ${ }^{\prime}$, and the antisense primer, $5^{\prime}$-CAGAGATCTTCACTGCATTGGCTA-3', were synthesized by Shanghai Sangon Biological Engineering Technology and Services Co., Ltd (Shanghai, China). The dual-labeled probe, 5'-6-carboxy fluorescein-CAGGCATCACCAGGAAGAAGACCTTTAAGGA-6-carboxy tetramethylrhodamine3', was synthesized by PE Biosystems (Foster City, CA, USA).

\section{Measurement of total plasma nitrate and nitrite}

$\mathrm{NO}_{x}$ is the total sum of nitrite $\left(\mathrm{NO}_{2}^{-}\right)$and nitrate $\left(\mathrm{NO}_{3}^{-}\right)$anions. $\mathrm{NO}_{x}$ levels were measured in plasma by an NO chemiluminescence detector (NOA 280; Sievers, Boulder City, CO, USA). Briefly, rat plasma samples (1:5 dilution) were filtered through Ultrafree- 4 filters and centrifuged for $1 \mathrm{~h}$ at $2500 \mathrm{~g}$. After removing high molecular proteins, the plasma samples together with $\mathrm{NO}_{3}{ }^{-}$ standard solutions were incubated with Tris buffer $\left(20 \mathrm{mmoll}^{-1}, \mathrm{pH}\right.$ 7.6) containing nitrate reductase $10 \mathrm{mU}$, NADPH $40 \mu \mathrm{moll}^{-1}$ and FAD $1 \mu \mathrm{moll}^{-1}$ for $1 \mathrm{~h}$ at $37^{\circ} \mathrm{C}$ to convert $\mathrm{NO}_{3}{ }^{-}$into $\mathrm{NO}_{2}{ }^{-}$. Samples now containing $\mathrm{NO}_{2}{ }^{-}$ were then reduced to $\mathrm{NO}$ in a purge vessel containing potassium iodide $(1 \%$ in acetic acid) as described earlier ${ }^{30}$ to determine $\mathrm{NO}_{x}$.

\section{Statistical analysis}

All values are presented as mean \pm s.d. The statistical significance of differences among groups was evaluated by one-way analysis of variance. All tests were performed using the SigmaStat statistical program (SPSS, Chicago, IL, USA). Significance was determined by $P$-values $<0.05$.

\section{RESULTS}

\section{Plasma FFAs, ROS, nitrotyrosine and GSH}

Measurements for arterial plasma FFAs were taken before and after the infusion (Table 1). The 4-h infusion of $20 \%$ Intralipid+heparin significantly increased arterial plasma FFAs from $345.4 \pm 86.6$ to $1146.4 \pm 336.6 \mu \mathrm{moll}^{-1}$ in the FFA group $(P<0.05)$ and from $340.6 \pm 90.5$ to $1131.0 \pm 230.4 \mu \mathrm{moll}^{-1}$ in the NAC group $(P<0.05)$. There was no significant difference between FFA levels in the NC group (337.9 \pm 97.9 vs. $340.2 \pm 103.6 \mu \mathrm{moll}^{-1}$, respectively; $\left.P>0.05\right)$.

Table 1 FFA, ROS, nitrotyrosine and GSH concentrations in the NC, FFA and NAC groups

\begin{tabular}{lccc}
\hline & NC group & FFA group & NAC group \\
\hline FFA $\left(\mu \mathrm{mol} \mathrm{I}^{-1}\right)$ & $340.2 \pm 103.6$ & $1146.4 \pm 336.6^{*}$ & $1131.0 \pm 230.4^{*}$ \\
ROS $\left(\mathrm{U} \mathrm{ml}^{-1}\right)$ & $452.4 \pm 90.5$ & $864.3 \pm 135.4^{*}$ & $480.5 \pm 110.5$ \\
Nitrotyrosine $\left(\mathrm{nmol} \mathrm{I}^{-1}\right)$ & $5.53 \pm 0.43$ & $8.05 \pm 1.69 *$ & $5.89 \pm 0.89$ \\
GSH $\left(\mathrm{mg} \mathrm{l}^{-1}\right)$ & $171.9 \pm 60.5$ & $153.1 \pm 55.9 *$ & $166.5 \pm 40.5$ \\
\hline
\end{tabular}

Abbreviations: FFA, free fatty acids; GSH, reduced glutathione hormone; NAC, $\mathrm{N}$-acetylcysteine; NC, control group; ROS, reactive oxygen species.

Data are mean \pm s.d. ${ }^{*} P<0.05$ vs. all other groups.
Compared with the NC group, ROS and nitrotyrosine concentrations in the FFA group were significantly increased after $4 \mathrm{~h}$ infusion of $20 \%$ Intralipid+heparin $(P<0.05)$, and GSH concentrations in the FFA group were significantly decreased $(P<0.05)$. ROS, nitrotyrosine and GSH concentrations in the NAC group were in between those in the NC and FFA groups (Table 1).

\section{Hyperinsulinemic-euglycemic clamp}

The GIR used to maintain euglycemia for the three groups can be seen in Figure 1. For the NC group, the GIR increased from 0 to $3.9 \pm 0.3 \mathrm{mg} \mathrm{kg}^{-1} \mathrm{~min}^{-1}$ at $20 \mathrm{~min}$ to $13.4 \pm 0.5 \mathrm{mg} \mathrm{kg}^{-1} \mathrm{~min}^{-1}$ at $120 \mathrm{~min}$, whereas the GIR for the FFA group increased from $2.3 \pm 0.4 \mathrm{mg} \mathrm{kg}^{-1} \mathrm{~min}^{-1}$ at $20 \mathrm{~min}$ to $5.3 \pm 0.6 \mathrm{mg} \mathrm{kg}^{-1} \mathrm{~min}^{-1}$ at $120 \mathrm{~min}$. The differences in GIRs to maintain euglycemia became significant as early as $20 \mathrm{~min}$ after the commencement of the insulin infusion. There was no significant difference between the NC and NAC groups (Figure 1).

\section{BP}

The baseline value of systolic BP was $140 \pm 20 \mathrm{~mm} \mathrm{Hg}$, with diastolic BP $113 \pm 10 \mathrm{~mm} \mathrm{Hg}$, and the baseline heart rate was $414 \pm 43$ b.p.m. The Intralipid+heparin infusion resulted in a significant increase in all three variables, especially during the final $2 \mathrm{~h}$ of the infusion (Figure 2). At the end of the $4 \mathrm{~h}$ infusion, systolic $(11.5 \pm 2.2 \mathrm{~mm} \mathrm{Hg})$ and diastolic $(6.0 \pm 1.2 \mathrm{~mm} \mathrm{Hg}) \mathrm{BP}$ increased, and the heart rate also increased ( $9.8 \pm 1.5$ b.p.m). A 4 -h infusion of saline did not alter systolic or diastolic BP. In the NAC group, there was no change in systolic and diastolic BP during the 4-h infusion of Intralipid+heparin and NAC. There was no significant difference between the NC and NAC groups.

\section{Organ chamber experiment}

Aortic rings from the FFA group rats tended to show worse EDV in response to graded concentrations of ACh than those from control rats (Figure 3a). Elevated FFAs reduced the relaxation observed at the highest concentration of ACh when compared with control aortic rings ( $54.8 \pm 2.5$ vs. $85.0 \pm 3.2 \%$, respectively; $P<0.05)$. In the NAC group, ACh-induced relaxation was slightly reduced when compared with the NC group. However, this reduction was significantly lower in magnitude when compared with the FFA group; the $E_{\max }$ response was $72.8 \pm 2.1 \%$. In contrast, endothelium-independent vasodilation (EIV) responses in aortic rings from NC, FFA and NAC group rats to the

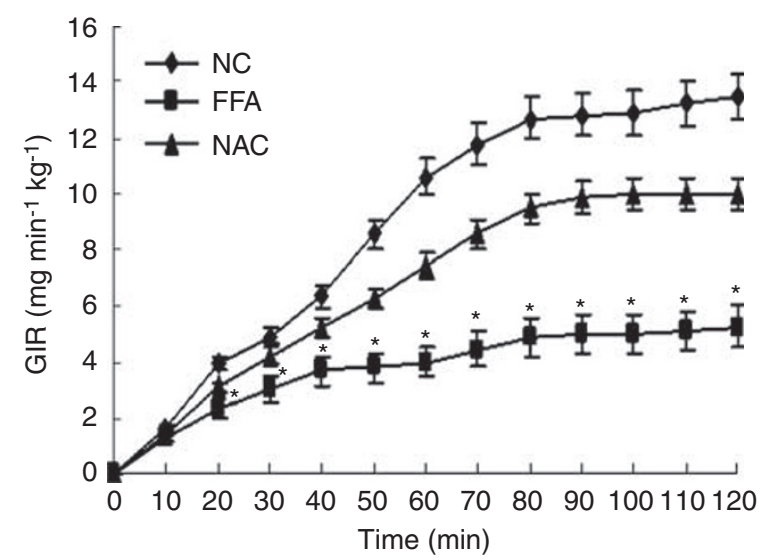

Figure 1 Glucose infusion rate (GIR) for the control (NC; $\bullet$ ), free fatty acid $(F F A ; \boldsymbol{\square})$ and the $\mathrm{N}$-acetylcysteine (NAC; $\mathbf{\Lambda})$ groups. Values are mean \pm s.d. ${ }^{*} P<0.05$ vs. NC group. 

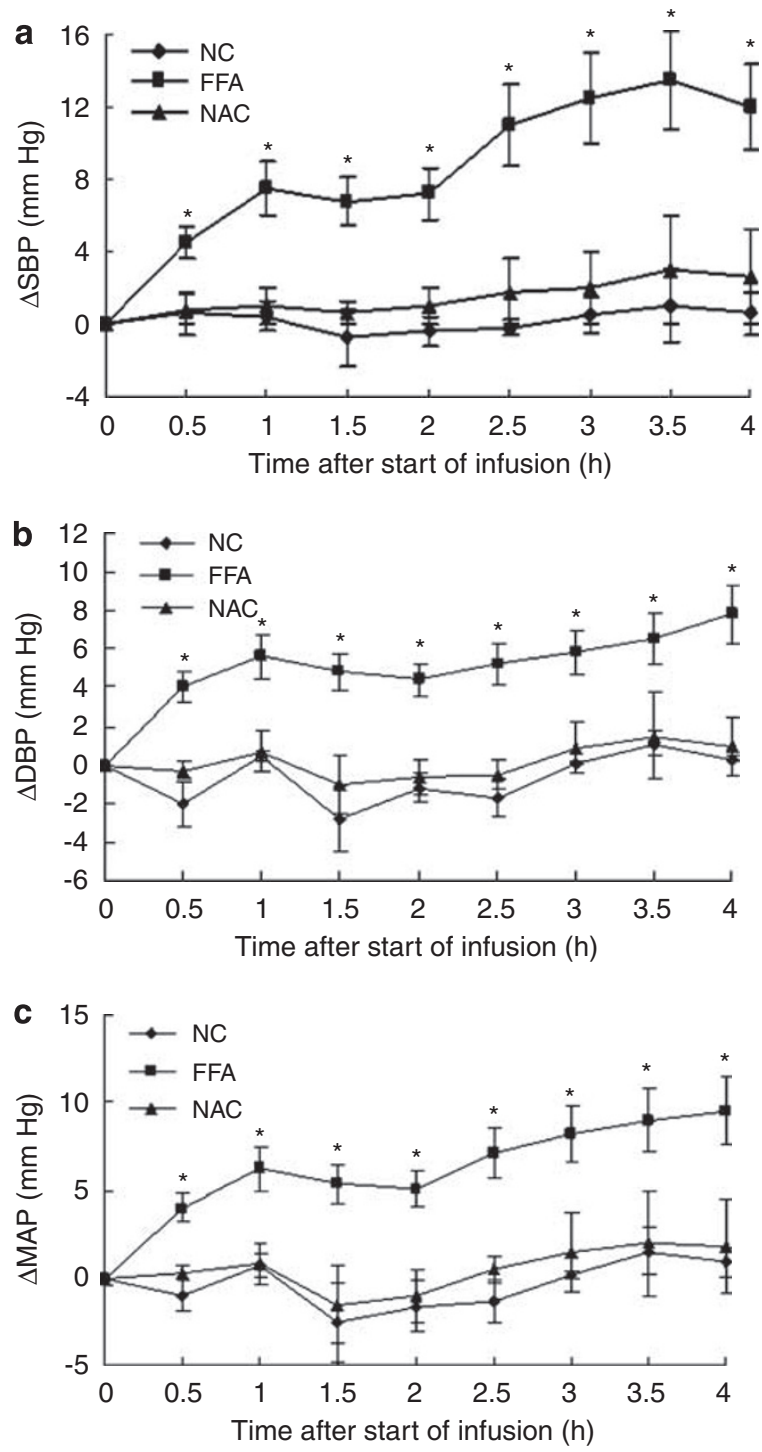

Figure 2 Change from baseline in systolic blood pressure $(\triangle \mathrm{SBP})$ (a), diastolic blood pressure $(\triangle \mathrm{DBP})(\mathbf{b})$ and mean arterial pressure $(\triangle \mathrm{MAP})$ (c) in rats infused with Intralipid+heparin $(\boldsymbol{\square}, N=22)$, saline $(\bullet, N=20)$ or with Intralipid+heparin and NAC $(\boldsymbol{\Delta}, N=23) .{ }^{*} P<0.05$ compared with saline.

NO-generating SNP were nearly identical; the $E_{\max }$ responses were $99.4 \pm 1.7,97.4 \pm 1.0$ and $98.1 \pm 1.4 \%$, respectively.

\section{eNOS enzymatic activity and eNOS mRNA expression}

Elevated FFAs markedly decreased the eNOS enzymatic activity. This effect was redressed by NAC (Figure 4a). The eNOS activity of endothelial cells in the FFA group was significantly lower than that in the NC group $(0.50 \pm 0.62$ vs. $0.96 \pm 0.66 \mathrm{pmol}$ citrulline per $\mathrm{mg}$ protein, respectively; $P<0.05)$. The eNOS activity in the NAC group was $0.88 \pm 0.64 \mathrm{pmol}$ citrulline per $\mathrm{mg}$ protein. Moreover, eNOS mRNA expressions through the quantitative real-time PCR analysis provided further evidence to support the above observation. eNOS mRNA expression was significantly decreased in the FFA group compared with the NC group; elevated plasma FFAs reduced the eNOS gene expression by $41.2 \%(P<0.05)$. NAC administration resulted in elevated eNOS mRNA expression, and the expression of eNOS gene was downregulated by $23.1 \%(P<0.05$; Figure $4 b)$.

\section{Total plasma nitrate and nitrite}

There was no significant difference between the $\mathrm{NO}_{2}{ }^{-} / \mathrm{NO}_{3}{ }^{-}$levels in the three groups before the start of infusions (Figure 5). Compared with the $\mathrm{NC}$ group, $\mathrm{NO}_{2}{ }^{-} / \mathrm{NO}_{3}{ }^{-}$levels in the $\mathrm{FFA}$ group were significantly decreased after $4 \mathrm{~h}$ infusion of $20 \%$ Intralipid+ heparin (19.3 \pm 2.9 vs. $14.3 \pm 1.9 \mu \mathrm{moll}^{-1}$, respectively; $\left.P<0.05\right)$. NAC administration increased $\mathrm{NO}_{2}{ }^{-} / \mathrm{NO}_{3}{ }^{-}$levels $(17.9 \pm 1.6$ vs. $14.3 \pm 1.9 \mu \mathrm{moll}^{-1}$, respectively; $\left.P<0.05\right)$.

\section{DISCUSSION}

This study showed that an infusion of Intralipid+heparin for $4 \mathrm{~h}$ increased BP in rats. In the NAC group, systolic and diastolic BP did not increase significantly. In aortic endothelial cells, EDV and NO production were impaired, and eNOS mRNA expression and activity were significantly decreased when FFAs were elevated in the FFA group. NAC administration improved EDV and NO production and caused elevation in eNOS activity and mRNA expression when compared with the FFA group. In addition, the biomarkers of oxidative stress levels were significantly higher than in controls, and antioxidant levels decreased significantly in the FFA group. There was no difference in the NC and NAC groups.

There are two main types of methods used to measure BP in experimental hypertension studies, namely a noninvasive tail cuff $\mathrm{BP}$ recording and an intra-arterial recording. The noninvasive tail cuff $\mathrm{BP}$ recording in the rat does not require surgery, but it is less accurate and is typically used for chronic experiments. The intra-arterial recording, regarded as the 'gold standard' method, can be performed continuously and is more accurate, although it is technically more demanding and invasive. As such, it is usually used for acute experiments. The intra-arterial recording was used to monitor BP in this study, and the results are more accurate and less influenced by outside factors.

There is some earlier evidence that high levels of FFAs can directly elevate BP. Stojiljkovic et al. ${ }^{5}$ reported that an infusion of Intralipid+heparin for $4 \mathrm{~h}$ induced a significant increase in systolic $(13.5 \pm 2.1 \mathrm{~mm} \mathrm{Hg})$ and diastolic $(8.0 \pm 1.5 \mathrm{~mm} \mathrm{Hg})$ BP in normal volunteers. In minipigs, $\mathrm{BP}$ and vascular resistance in most tissue beds increased when plasma levels of NEFAs were elevated during an infusion of Intralipid+heparin. ${ }^{6}$ In this study, BP was increased after the 4-h infusion of Intralipid+heparin used to increase plasma FFAs, with a significant increase in systolic $(11.5 \pm 2.2 \mathrm{~mm} \mathrm{Hg})$ and diastolic $(6.0 \pm 1.2 \mathrm{~mm} \mathrm{Hg}) \mathrm{BP}$, as well as heart rate $(9.8 \pm 1.5$ b.p.m.). In contrast, BP did not change in rats during the 4-h saline infusion. These data are consistent with earlier studies, and show that high FFA levels can directly induce elevated BP. But, perhaps, there is still one limitation we should discuss referring to this issue. Earlier studies indicated that anesthesia induced by pentobarbital could decrease the level of BP. Shimokawa et al. ${ }^{31}$ showed that pentobarbital sodium $\left(30 \mathrm{mg} \mathrm{kg}^{-1}\right.$, i.v.) caused a decrease in BP and heart rate. These effects remained significant until $30 \mathrm{~min}$ after the injection. Between 1 and $5 \mathrm{~h}$, mean arterial pressure recovered to the preanesthetic control value. A single bolus dose of pentobarbital $\left(20 \mathrm{mg} \mathrm{kg}^{-1}\right.$, i.v. $)$ produced a transient hypotension, followed by mild, although longer-lasting, hypotension. ${ }^{32}$ Pentobarbital may induce its circulatory effects by suppressing sympathetic activity, depressing autonomic function and attenuating the ability of the baroreflex. ${ }^{33-35}$ However, such limitation could be at least partly redressed by the involvement of the control group. Furthermore, BP measurement was also performed in such time as a 60 -min equilibration period was allowed after surgery for stabilization of BP.

Increased concentrations of plasma FFA are well known to induce IR through the inhibition of glucose transport activity. ${ }^{36,37}$ In this 

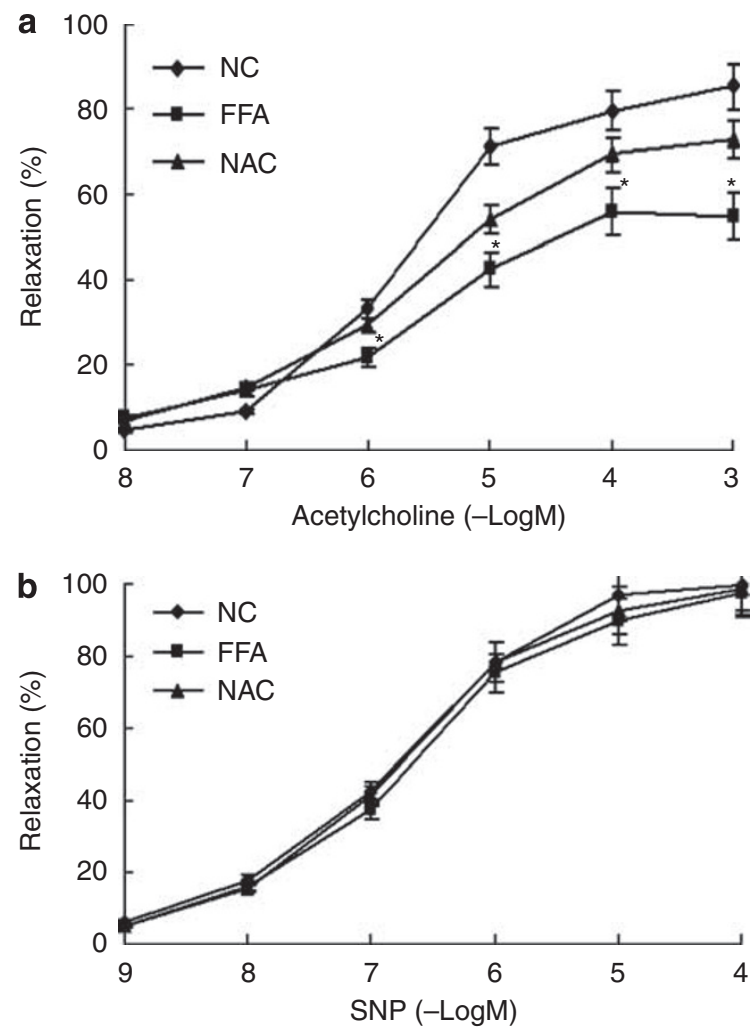

Figure 3 Concentration-response curves for acetylcholine (ACh)-evoked endothelium-dependent vasodilation (EDV) (a) and sodium nitroprusside (SNP)-evoked endothelium-independent vasodilation (EIV) (b) of rat isolated aortic rings. Values are mean \pm s.d., $N=15$. ${ }^{*} P<0.05$ vs. the NC group.

study, GIR was significantly reduced after the 4-h infusion of Intralipid+heparin used to raise plasma FFAs. These data suggest that elevated plasma FFAs can really cause IR, and this finding is similar to that reported in other studies. ${ }^{38-40}$

In one study, Steinberg et al. ${ }^{9}$ reported that systolic BP increased by 3-5\% when plasma NEFAs were increased with Intralipid+heparin, and that elevated plasma NEFAs in normal volunteers impaired regional EDV. An acute increase in the serum levels of NEFAs was also shown to decrease EDV. ${ }^{41}$ In this study, increasing FFA levels induced EDV dysfunction, but did not impair EIV. These data suggest a relationship between endothelial dysfunction and high FFA levels, and moreover, that EDV impairment may play an important role in elevated BP caused by high FFA levels.

The functional correlate of FFA-induced decreased aortic NO production was examined by investigating EDV and EIV responses ex vivo. NO plays a key role in the maintenance of vascular tone and BP. $^{42,43}$ Some studies have shown that FFAs can impair eNOS activity and EDV in vitro. In humans, EDV and NO production were impaired when plasma NEFAs were increased with Intralipid+heparin. ${ }^{8-11}$ In most biological situations, $\mathrm{NO}$ is largely oxidized to nitrate $\left(\mathrm{NO}_{3}{ }^{-}\right)$ and nitrite $\left(\mathrm{NO}_{2}^{-}\right)$, with the measurement of $\mathrm{NO}_{x}$ production seen as an index of endothelial dysfunction in many diseases. In this study, the increased arterial plasma FFAs after $4 \mathrm{~h}$ infusion of Intralipid+heparin significantly decreased $\mathrm{NO}_{2}{ }^{-} / \mathrm{NO}_{3}{ }^{-}$levels, suggesting that $\mathrm{NO}$ production was impaired when plasma FFAs were increased. In the FFA group, eNOS mRNA expression and activity were also significantly lower than those in the NC group, suggesting that increased FFAs markedly impaired eNOS mRNA expression and activity and thus induced endothelial NO production. NO has been implicated in the
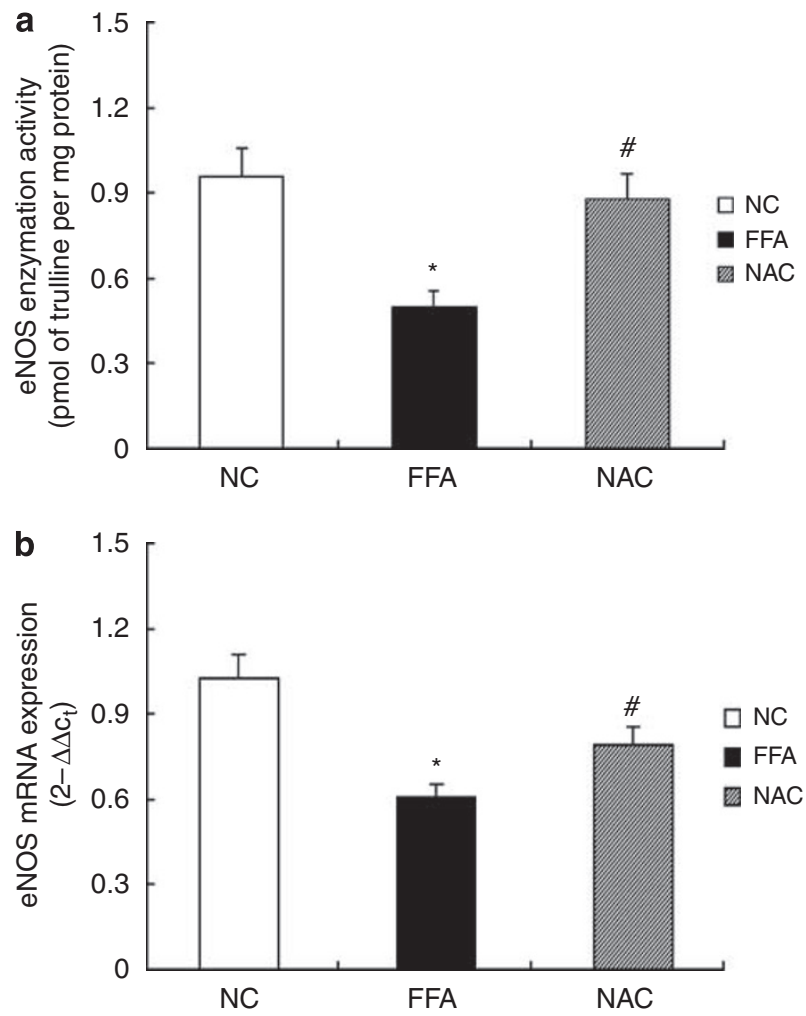

Figure 4 Endothelial nitric oxide synthase (eNOS) enzymatic activity (a) and eNOS mRNA expression (b) of the three groups. The eNOS enzymatic activity was determined by measuring the conversion of ${ }^{14} \mathrm{C}$-arginine into ${ }^{14} \mathrm{C}$-citrulline. Expression of eNOS in rat endothelial cells was determined by a quantitative real-time PCR analysis. Each bar represents the mean \pm s.d. ${ }^{*} P<0.05$ vs. the NC group, ${ }^{\#} P<0.05$ vs. the FFA group.

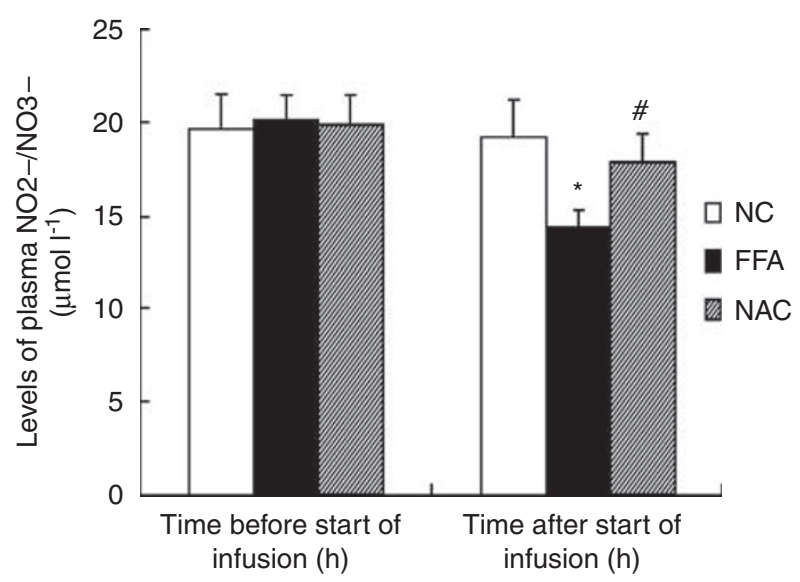

Figure 5 Levels of plasma $\mathrm{NO}_{2}-/ \mathrm{NO}_{3}{ }^{-}$of the three groups before and after $4 \mathrm{~h}$ infusion. Each bar represents the mean \pm s.d. ${ }^{*} P<0.05$ vs. the NC group, ${ }^{\#} P<0.05$ vs. the FFA group.

regulation of $\mathrm{BP}$ and regional blood flow. A study reported that mice lacking the gene for eNOS show hypertension. ${ }^{44} \mathrm{NO}$, a potent vasodilator produced by endothelial cells, has been proposed as a major form of endothelium-dependent relaxing factor, which mediates vascular relaxation in response to ACh. Therefore, a resulting impairment in EDV is involved in the pathophysiology of hypertension.

ROS, nitrotyrosine and GSH are biomarkers of oxidative stress. Experimental studies have confirmed that hypertension is related to 
oxidative stress. ${ }^{13,14}$ Increasing plasma FFAs with a short-term infusion of Intralipid+heparin elevates $\mathrm{BP}$ and increases $\mathrm{F}_{2}$-isoprostanes, a biomarker of oxidative stress. ${ }^{5,12}$ In this study, ROS and nitrotyrosine concentrations in the FFA group were higher than those in the $\mathrm{NC}$ group, whereas GSH concentrations in the FFA group were lower than those in the NC group. Thus, increased FFAs can directly enhance oxidative stress in the rats. Meanwhile, after a 4-h infusion of Intralipid+heparin, BP was significantly increased. These data suggest a relationship between oxidative stress and elevated BP.

Although the mechanisms of oxidative stress-induced elevated BP are largely unknown, oxidative stress has been shown to induce not only endothelial dysfunction but also impair eNOS mRNA expression and NO production, which may cause further endothelial cell dysfunction. For example, Perticone et al. ${ }^{15}$ reported that obesity and body fat distribution induce endothelial dysfunction by oxidative stress, whereas FFA-induced endothelial dysfunction can be corrected by vitamin C. ${ }^{16}$ In this study, we also observed elevated FFA levels after an infusion of Intralipid+heparin for $4 \mathrm{~h}$, reduced eNOS mRNA expression and activity, decreased NO production and impaired EDV. Further, oxide levels were significantly increased and antioxidant levels were decreased. As an impairment in EDV is involved in the pathophysiology of hypertension, these data suggest that oxidative stress could contribute to endothelial dysfunction, leading to the elevated BP.

The antioxidant and glutathione precursor NAC enhances the biological effects of NO by decreasing ROS levels, thus preventing peroxynitrate formation, and by protecting NO (formation of $S$-nitrosothiol compounds) from free radical-mediated destruction. ${ }^{45}$ The chronic administration of NAC protected against vascular dysfunction and reduced BP in hypertensive rats. ${ }^{46-48}$ The antihypertensive effect of NAC was quite likely mediated by increased NOdependent vasodilation. ${ }^{49}$ In this study, an infusion of NAC, an antioxidant and glutathione precursor, prevented the increase in oxidative stress, restored $\mathrm{NO}$ availability and prevented the elevation of arterial BP and heart rate through mechanism(s) that may involve the restoration of $\mathrm{NO}$ bioavailability and antioxidant capacity.

In conclusion, this study suggests that elevated FFA concentrations can directly and independently reduce endothelial NO production and eNOS mRNA expression and activity, which may impair EDV, and thus increase BP. Further, blood vessel endothelial cell oxidative stress may play an important role in this link. Although the mechanism of FFA-induced hypertension remains to be defined, these data suggest that clinical strategies to reduce FFA concentrations would have beneficial cardiovascular effects.

\section{ACKNOWLEDGEMENTS}

This work was supported by generous research grants from the Clinical Research Institute of China-Japan Friendship Hospital. We are deeply grateful to MJ Zhao and ZX Zhang (the Medical Research Center, Dongzhimen Hospital Affiliated to Beijing University of Chinese Medicine) for excellent technical assistance.

\section{CONFLICT OF INTEREST}

None.

1 Sheu WH, Jeng CY, Shieh SM, Fuh MM. Suppression of non-esterified fatty acid concentrations by insulin inpatients with hypertension. Chin Med J 1995; 56: 367-372.
2 Fagot-Campagna A, Balkau B, Simon D, Warnet JM, Claude JR, Ducimetière $P$, Eschwège $E$. High free fatty acid concentration: an independent risk factor for hypertension in the Paris Prospective Study. Int J Epidemiol 1998; 27: 808-813.

3 Egan BM, Hennes MM, Stepniakowski KT, O'Shaughnessy IM, Kissebah AH, Goodfriend TL. Obesity hypertension is relate more to insulin's fatty acid than glucose action. Hypertension 1996; 27: 723-728.

4 Wilde DW, Massey KD, Walker GK, Vollmer A, Grekin RJ. High-fat diet elevates blood pressure and cerebrovascular muscle $\mathrm{Ca}(2+)$ current. Hypertension 2000; 35: 832-837.

5 Stojiljkovic MP, Zhang D, Lopes HF, Lee CG, Goodfriend TL, Egan BM. Hemodynamic effects of lipids in humans. Am J Physiol Regul Integr Comp Physiol 2001; 280: R1674-R1679.

6 Bulow J, Madsen J, Hojgaard L. Reversibility of the effects on local circulation of high lipid concentrations in blood. Scand J Clin Lab Invest 1990; 50: 291-296.

7 Grekin RJ, Vollmer AP, Sider RS. Pressor effects of portal venous oleate infusion. A proposed mechanism for obesity hypertension. Hypertension 1995; 26: 193-198.

8 Davda RK, Stepniakowski KT, Lu G, Ullian ME, Goodfriend TL, Egan BM. Oleic acid inhibits endothelial nitric oxide synthase by a protein kinase $\mathrm{C}$-independent mechanism. Hypertension 1995; 26: 764-770.

9 Steinberg HO, Tarshoby M, Monestel R, Hook G, Cronin J, Johnson A, Bayazeed B, Baron AD. Elevated circulating free fatty acid levels impair endothelium-dependent vasodilation. J Clin Invest 1997; 100: 1230-1239.

10 Steinberg HO, Paradisi G, Hook G, Crowder K, Cronin J, Baron AD. Free fatty acid elevation impairs insulin-mediated vasodilation and nitric oxide production. Diabetes 2000; 49: 1231-1238.

11 Baron AD, Quon MJ. Insulin action and endothelial function. In: Reaven GM, Laws A (eds), Insulin resistance, the metabolic syndrome $X$. Humana Press, Totowa, 1999, pp 247-266.

12 Stojiljkovic MP, Lopes HF, Zhang D, Morrow JD, Goodfriend TL, Egan BM. Increasing plasma fatty acids elevates $\mathrm{F}_{2}$-isoprostanes in humans: implications for the cardiovascular risk factor cluster. J Hypertens 2002; 20: 1215-1221.

13 Vaziri ND, Wang XQ, Oveisi F, Rad B. Induction of oxidative stress by glutathione depletion causes severe hypertension in normal rats. Hypertension 2000; 36 : 142-146.

14 Lopes HF, Martin KL, Nashar K, Morrow JD, Goodfriend TL, Egan BM. DASH diet lowers blood pressure and lipid-induced oxidative stress in obesity. Hypertension 2003; 41: 422-430.

15 Perticone F, Ceravolo R, Candigliota M, Ventura G, lacopino S, Sinopoli F, Mattioli PL. Obesity and body fat distribution induce endothelial dysfunction by oxidative stress: protective effect of vitamin C. Diabetes 2001; 50: 159-165.

16 Pleiner J, Schaller G, Mittermayer F, Bayerle-Eder M, Roden M, Wolzt M. FFA-induced endothelial dysfunction can be corrected by vitamin C. J Clin Endocrinol Metab 2002; 87: 2913-2917.

17 Inoguchi T, Li P, Umeda F, Yu HY, Kakimoto M, Imamura M, Aoki T, Etoh T, Hashimoto $T$, Naruse M, Sano $H$, Utsumi $H$, Nawata $H$. High glucose level and free fatty acid stimulate reactive oxygen species production through protein kinase $\mathrm{C}$-dependent activation of $\mathrm{NAD}(\mathrm{P}) \mathrm{H}$ oxidase in cultured vascular cells. Diabetes 2000; 49: 1939-1945.

18 Tang R, Liu H, Wang T, Huang K. Mechanisms of selenium inhibition of cell apoptosis induced by oxysterols in rat vascular smooth muscle cells. Arch Biochem Biophys 2005; 441: 16-24.

19 Sedlak J, Lindsay RH. Estimation of total, protein-bound, and nonprotein sulfhydryl groups in tissue with Ellman's reagent. Anal Biochem 1968; 25: 192-205.

20 Snel CA, Zhao Y, Mulder GJ, Pang KS. Methods for the quantitation of bromosulfophtalein and its glutathione conjugate in biological fluids. Anal Biochem 1993; 212: 28-34.

21 Del Guerra S, Lupi R, Marselli L, Masini M, Bugliani M, Sbrana S, Torri S, Pollera M, Boggi U, Mosca F, Del Prato S, Marchetti P. Functional and molecular defects of pancreatic islets in human type 2 diabetes. Diabetes 2005; 54: 727-735.

22 Quagliaro L, Piconi L, Assaloni R, Martinelli L, Motz E, Ceriello A. Intermittent high glucose enhances apoptosis related to oxidative stress in human umbilical vein endothelial cells: the role of protein kinase $\mathrm{C}$ and $\mathrm{NAD}(\mathrm{P}) \mathrm{H}$-oxidase activation. Diabetes 2003; 52: 2795-2804.

23 Hevener AL, Reichart D, Janez A, Olefsky J. Thiazolidinedione treatment prevents free fatty acid-induced insulin resistance in male wistar rats. Diabetes 2001; 50: 2316-2322.

24 Youd JM, Rattigan S, Clark MG. Acute impairment of insulin-mediated capillary recruitment and glucose uptake in rat skeletal muscle in vivo by TNF-alpha. Diabetes 2000; 49: 1904-1909.

25 Ajay M, Gilani AH, Mustafa MR. Effects of flavonoids on vascular smooth muscle of the isolated rat thoracic aorta. Life Sci 2003; 74: 603-612.

26 Ajay M, Achike FI, Mustafa AM, Mustafa MR. Direct effects of quercetin on impaired reactivity of spontaneously hypertensive rat aortae: comparative study with ascorbic acid. Clin Exp Pharmacol Physiol 2006; 33: 345-350.

27 Ajay M, Achike FI, Mustafa AM, Mustafa MR. Effect of quercetin on altered vascular reactivity in aortas isolated from streptozotocin-induced diabetic rats. Diabetes Res Clin Pract 2006; 73: 1-7.

28 Gentile MT, Vecchione C, Marino G, Aretini A, Di Pardo A, Antenucci G, Maffei A, Cifelli G, Iorio L, Landolfi A, Frati G, Lembo G. Resistin impairs insulin-evoked vasodilation. Diabetes 2008; 57: 577-583.

29 Chu Y, Heistad DD, Knudtson KL, Lamping KG, Faraci FM. Quantification of mRNA for endothelial NO synthase in mouse blood vessels by real-time polymerase chain reaction. Arterioscler Thromb Vasc Biol 2002; 22: 611-616. 
30 Dooley A, Gao B, Bradley N, Abraham DJ, Black CM, Jacobs M, Bruckdorfer KR. Abnormal nitric oxide metabolism in systemic sclerosis: increased levels of nitrated proteins and asymmetric dimethylarginine. Rheumatology 2006; 45: 676-684.

31 Shimokawa A, Kunitake T, Takasaki M, Kannan H. Differential effects of anesthetics on sympathetic nerve activity and arterial baroreceptor reflex in chronically instrumented rats. J Auton Nerv Syst 1998; 72: 46-54.

32 Yang CC, Kuo TB, Chan SH. Auto- and cross-spectral analysis of cardiovascular fluctuations during pentobarbital anesthesia in the rat. Am J Physiol 1996; 270: H575-H582.

33 Cox RH, Bagshaw RJ. Influence of anesthesia on the response to carotid hypotension in dogs. Am J Physiol 1979; 237: H424-H432.

34 Peiss CN, Manning JW. Effects of sodium pentobarbital on electrical and reflex activation of the cardiovascular system. Circ Res 1964; 14: 228-235.

35 Stornetta RL, Guyenet PG, McCarty RC. Autonomic nervous system control of heart rate during baroreceptor activation in conscious and anesthetized rats. J Auton Nerv Syst 1987; 20: 121-127.

36 Dresner A, Laurent D, Marcucci M, Griffin ME, Dufour S, Cline GW, Slezak LA, Andersen DK, Hundal RS, Rothman DL, Petersen KF, Shulman GI. Effects of free fatty acids on glucose transport and IRS-1-associated phosphatidylinositol 3-kinase activity. J Clin Invest 1999; 103: 253-259.

37 Kelley DE, Mokan M, Simoneau JA, Mandarino LJ. Interaction between glucose and free fatty acid metabolism in human skeletal muscle. J Clin Invest 1993; 92: 91-98.

38 Ferrannini E, Barrett EJ, Bevilacqua S, DeFronzo RA. Effect of fatty acids on glucose production and utilization in man. J Clin Invest 1983; 72: 1737-1747.

39 Griffin ME, Marcucci MJ, Cline GW, Bell K, Barucci N, Lee D, Goodyear LJ, Kraegen EW, White MF, Shulman GI. Free fatty acid-induced insulin resistance is associated with activation of protein kinase $\mathrm{C}$ theta and alterations in the insulin signaling cascade. Diabetes 1999; 48: 1270-1274.
40 Bevilacqua S, Bonadonna R, Buzzigoli G, Boni C, Ciociaro D, Maccari F, Giorico MA, Ferrannini E. Acute elevation of free fatty acid levels lead to hepatic insulin resistance in obese subjects. Metabolism 1987; 36: 502-506.

41 Lind L, Fugmann A, Branth S, Vessby B, Millgård J, Berne C, Lithell H. The impairment in endothelial function induced by non-esterified fatty acids can be reversed by insulin. Clin Sci (Lond) 2000; 99: 169-174.

42 Berry C, Brosnan MJ, Fennell J, Hamilton CA, Dominiczak AF. Oxidative stress and vascular damage in hypertension. Curr Opin Nephrol Hypertens 2001; 10: 247-255. 43 Wilcox CS. Reactive oxygen species: roles in blood pressure and kidney function. Curr Hypertens Rep 2002; 4: 160-166.

44 Huang PL, Huang Z, Mashimo H, Bloch KD, Moskowitz MA, Bevan JA, Fishman MC. Hypertension in mice lacking the gene for endothelial nitric oxide synthase. Nature 1995; 377: 239-242.

45 Lahera V, Khraibi AA, Romero JC. Sulfhydryl group donors potentiate the hypotensive effect of acetylcholine in rats. Hypertension 1993; 22: 156-160.

46 Cabassi A, Dumont EC, Girouard H, Bouchard JF, Le Jossec M, Lamontagne D, Besner $\mathrm{JG}$, de Champlain J. Effects of chronic $\mathrm{N}$-acetylcysteine treatment on the actions of peroxynitrite on aortic vascular reactivity in hypertensive rats. J Hypertens 2001; 19 : 1233-1244.

47 Zicha J, Dobesová Z, Kunes J. Antihypertensive mechanisms of chronic captopril or $\mathrm{N}$ acetylcysteine treatment in L-NAME hypertensive rats. Hypertens Res 2006; 29: 1021-1027.

48 Rauchová $\mathrm{H}$, Pechánová $\mathrm{O}$, Kunes J, Vokurková $\mathrm{M}$, Dobesová Z, Zicha J. Chronic Nacetylcysteine administration prevents development of hypertension in $N$ (omega)-nitroL-arginine methyl ester-treated rats: the role of reactive oxygen species. Hypertens Res 2005; 28: 475-482.

49 Girouard H, Chulak C, Wu L, Lejossec M, de Champlain J. N-acetylcysteine improves nitric oxide and alpha-adrenergic pathways in mesenteric beds of spontaneously hypertensive rats. Am J Hypertens 2003; 16: 577-584. 